Muséologies

Les cahiers d'études supérieures

muséologies

\title{
Christine St-Pierre, ministre de la Culture, des Communications et de la Condition féminine
}

\section{Louise Champoux-Paillé}

Volume 4, numéro 1, automne 2009

URI : https://id.erudit.org/iderudit/1033530ar

DOI : https://doi.org/10.7202/1033530ar

Aller au sommaire du numéro

Éditeur(s)

Association Québécoise de Promotion des Recherches Étudiantes en Muséologie (AQPREM)

ISSN

1718-5181 (imprimé)

1929-7815 (numérique)

Découvrir la revue

Citer ce document

Champoux-Paillé, L. (2009). Christine St-Pierre, ministre de la Culture, des Communications et de la Condition féminine. Muséologies, 4(1), 34-39.

https://doi.org/10.7202/1033530ar d'utilisation que vous pouvez consulter en ligne. 
Dialogue un

\section{Christine St-Pierre,}

\section{ministre de la Culture,}

\section{des Communications}

\section{et de la Condition féminine}

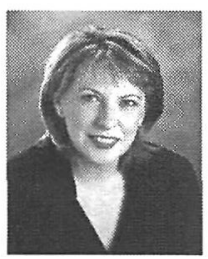

[Réalisé par Louise Champoux-Paillé

le 20 novembre 2009]

Employée à Radio-Canada de 1976 à 2007, madame Christine St-Pierre y a été successivement journaliste, courriériste parlementaire à Québec, à Ottawa et correspondante à Washington. Élue députée de la circonscription de l'Acadie en 2007, elle fut nommée ministre de la Culture, des Communications et de la Condition féminine et ministre responsable de l'application de la Charte de la langue française. Réélue lors des élections de 2008 , le premier ministre Jean Charest l'invitait à occuper les mêmes fonctions dans son nouveau cabinet. Femme de terrain, elle ne veut pas être "Ministre de tour d'ivoire" mais plutôt une ministre qui a besoin de s'imprégner des besoins de ses diverses clientèles, "d'aller voir au rang des marguerites". 
Louise Cham pouX-Paillé

Dans le document intitulé « La culture au cœur du développement durable», vous écrivez: «je crois profondément que la culture constitue une force vitale des sociétés, une force vive et positive qui, faisant le pont entre la créativité et l'identité des communautés, permet que chaque nation, chaque région, chaque individu participent à l'édification d'une communauté viable». Concrètement, comment voyez-vous l'action de votre ministère dans ce concept de développement durable?

\section{Christine ST-PierRe}

D'entrée de jeu, je me permettrai de rappeler que le Québec est l'un des rares États à s'être donné à la fois une législation et une politique spécifiquement sur la question. Dévoilée en janvier 2008, la stratégie gouvernementale de développement durable demande à tous les ministères, organismes et entreprises del'administration de préciser leur apport à son déploiement dans un plan d'action. Mon ministère a proposé quinze interventions en rapport avec la gestion environnementale, l'aménagement du territoire, la préservation du patrimoine commun, la participation à la vie collective et l'équité sociale. Deux eléments principaux ont orienté notre réflexion. La sauvegarde du patrimoine culturel, désormais reconnue dans la Loi sur le développement durable comme l'un des seize principes qui doivent être pris en compte parl'ensemble du gouvernement, et la Convention sur la protection et la promotion de la diversité des expressions culturelles. Cette Convention qui a été adoptée par l'UNESCO en 2005, le Quebec a étéle premier État du monde àle sanctionner par un vote unanime à l'Assemblée nationale. Son entrée en vigueur en 2007 représente une avancée majeure pourle Québec, en particulier pour ses créateurs, ses institutions et ses industries culturelles.

Concrètement, cette orientation vers le développement durable signifie que toutes nos décisions et nos actions en matière de culture doivent être prises dans une perspective à long terme et non à court terme, c'est-à-dire dans une perspective de durabilité. Il faut quitter le paradigme de la "consommation jetable" pour celle de la "consommation durable».

Ainsi, à titre d'exemple, je citerai la remise en état de l'industrie montréalaise Angus. À cet égard, savez-vous que $20 \%$ des édifices construits au Canada avant 1920 ont été démolis pendant les années 1970 et 1980 et qu'il s'agit d'une perte inestimable d'eléments révelateurs de notre identité, facteurs de cohésion sociale et d'attractions touristiques dont les régions ne pourront plus jamais profiter. Plus important encore, des études canadiennes et américaines démontrent que la démolition et le remplacement d'anciens édifices par des constructions neuves augmentent la production de gaz à effet de serre. Une étude portant sur la Technopole Angus a comparé la remise en état de l'édifice et sa conversion adaptée en un complexe résidentiel à la construction d'un nouvel édifice au même endroit. L'étude a démontré que la remise en état a produit des émissions nettement 
inférieures pour deux gaz à effet de serre, le dioxyde de carbone $\left(\mathrm{CO}_{2}\right)$ et le dioxyde de souffre $\left(\mathrm{SO}_{2}\right)$ et consomme moins d'énergie.

La tendance à biffer le passé pour plonger dans la modernité particulièrement manifeste dansle dernier quart du vingtième siècle, a eu desimpacts lourds sur des biens porteurs d'une valeur identitaire incontestable d'où l'importance d'un regard neuf surnotre patrimoine culturel.

Louise Champoux-Paillé

Dans le plan de développement durable, le ministère insiste sur l'importance de sauvegarder et partager le patrimoine collectif. Quelles sont les actions susceptibles d'inciter à un meilleur partage des différents patrimoines collectifs et la création d'un nouveau patrimoine à l'image du Québec du $21^{\circ}$ siècle?

Christine ST-Pierre

Un tel enjeu repose, entre autres, sur la participation et l'engagement du plus grand nombre de citoyens. Le ministère souhaite une société participative. Il faut que les gens s'approprient les musées. Il est important qu'ils les visitent et les enrichissent de nouvelles idées, bref qu'ils en fassent un milieu où ils se retrouvent et où ils peuvent échanger. Les musées d'aujourd'hui sont d'ailleurs différents du siècle dernier.

La dimension multiethnique doit être davantage présente dans nos institutions culturelles. À titre d'exemple, j'ai récemment annoncé l'agrandissement de la Bibliothèque de l'arrondissement Ville St-Laurent qui permettra de redéployer ses activités en fonction des besoins de sa population d'aujourd'hui et de demain qui n'ont pas le même visage qu'hier.

Autre exemple, les investissements que nous effectuons dans le patrimoine bâti et le secteur culturel grace au Fonds du patrimoine culturel. Vous le savez, le Fonds du patrimoine culturel se finance à même une partie de la taxe sur le tabac. C'est lorsqu'on a eu terminé de payer la dette olympique que ma prédécesseure, madame Line Beauchamp, a eul'idée de dire: "Bien, plutôt qued'abandonner cette portion de taxe, pourquoi ne pas la conserver et la verser dans un fonds $d u$ patrimoine culturel? "Je ne veux pas fairel'apologie, loin de moi, desfumeurs, mais, bon, c'est à partir de la taxe surle tabac qu'on injecte del'argent dansle Fonds, et vraiment, là aussi, on parle d'une bouffée d'oxygène pour la restauration et la mise aux normes dü patrimoine bati. Ce Fonds vise également à intégrer l'art public aux enjeux de conservation ainsique de favoriser la diffusion des œuvres des collections muséales.

Ainsi, cet été, nous avons injecté plus de 7 millions de dollars pour aider les musées à renouveler leurs expositions permanentes. Si on souhaite attirer des gens nouveaux, il faut renouveler nos expositions permanentes. Quand on sait qu'une exposition permanente a une durée de $\sigma a ̀$ ans, il est important de voir à ce renouvellement. 
Il est également important de faire connaître les nouveaux talents québécois. À cet égard, je tiens à souligner l'initiative de Loto-Québec qui, annuellement, achète d'un artiste une œuvre permettant ainsi de faire connaître un nouveau talent tout en l'encourageant financièrement directement.

\section{Louise Cham poux-Paillé}

Plusieurs des emplois dans le domaine de la culture sont sous forme contractuelle, surtout en regard des nouveaux professionnels qui entrent sur le marché du travail. Ceci a un impact sur la conservation d'une main-d'œuvre qualifiée et motivée au sein du réseau muséal québécois. Quelle est votre lecture de la force de l'industrie culturelle au Québec et de ses occasions d'emplois?

\section{CHRISTINE ST-PIERRE}

En novembre dernier, $j$ 'assistais à une présentation de la Chambre de commerce du Montréal métropolitain portant surla culture à Montréal et ses impacts économiques. Cette présentation comportait des statistiques intéressantes que je souhaiterais partager avec vos lecteurs. On $y$ apprenait que la culture emploie près de 97 ooo personnes dans le Grand Montréal et génère des retombées directes de près de 8 milliards de dollars, soit $6 \%$ du produit intérieur brut (PIB) de la métropole. C'est, permettez-moi d'ajouter, un secteur qui a connu une croissance annuelle de 4,6\% par année en dix ans, soit presque trois fois plus que la moyenne globale du marché du travail, qui est de $1,7 \%$ sur cette période. De plus, en comparant ce secteur aux autres dans les "domaines du savoir", on constate que la culture se classe au deuxième rang, après les technologies de l'information, un secteur qui emploie environ 130 ooo personnes. Bref, ces chiffres témoignent bien, comme le dit la Chambre de commerce du Montréal métropolitain, des transformations structurelles qu'ont subies les économies montréalaise et quebécoise au cours de la dernière décennie. Alors que des pertes d'emploi importantes ont eu lieu dans certains secteurs traditionnels, notamment dans le secteur manufacturier, d'autres ont été créés dans d'autres sphères de l'économie, soit dans le secteur culturel. Permettez-moi d'ajouter que plus de 200 personnes travaillent dans le domaine de la culture au sein du gouvernement du Québec incluant les sociétés d'État et les institutions qui se retrouvent dans son giron immédiat.

Ce contexte d'emploi est particulièrement favorable à la relève dans le milieu culturel où plusieurs "baby-boomers" iront à la retraite dans les années à venir. Comme le disait mon collègue Sam Hamad, ministre québécois de l'Emploi et de la Solidarité, notre prochain défi visera à doter le Quebec d'un plan pour faire face aux problèmes de recrutement dans un contexte de déclin démographique, alors que nos besoins de main-d'œuvre font état de 700000 emplois à pourvoir de 2007 à 2011 ". Ces départs ne pourront être difficilement compensés par l'arrivée des jeunes et des immigrants. 
Je me souviens lorsque j'ai commencé à travaillerà Radio-Canada. J'y ai obtenu au départ un contrat de deux semaines et j'y ai fait carrière pendant près de trente ans. Je croyais que le domaine des communications serait le milieu où je me réaliserais le mieux et j'ai persévéré.

LOUISE Cham PouX-PAILlÉ

Enfin, quels sont les projets de votre ministère pour les prochaines années?

\section{Christine St-Pierre}

Mon ministère souhaite pour 2010 présenter à l'Assemblée nationale du Québec son projet de modernisation de la Loi sur les biens culturels. Ça fait un peu bizarre de dire "moderniser" en parlant de patrimoine, mais c'est réellement le cas. Notre Loi sur les biens culturels a déjà plus de 35 ans, et il faut faire en sorte qu'on l'adapte aux nouvelles réalités. Au cours des derniers mois, mes collaborateurs du ministère ainsi que moi-même avons effectué une tournée de toutes les régions du Québec pour aller chercher les commentaires au sujet $d u$ livre vert que nous avons rendu public au mois de janvier dernier. Et ensuite, j'ai fait 15 séances de consultation dans 12 villes du Québec. Je suis allée un peu partout. J'ai entendu 147 personnes et organismes pendant cette tournée de consultation. Et nous avons reçu 202 mémoires et 109 réponses au questionnaire en ligne. Il s'agit donc d'une vaste consultation. Et j'ai été très heureuse de voir à quel point les gens étaient très enthousiastes de venir discuter de la question du patrimoine.

Ces consultations nous ont permis d'identifier plusieurs améliorations potentielles que nous sommes en train d'évaluer. À titre d'exemple, quand on parle de citation, on voudrait ajouter une autre catégorie qui pourrait être une reconnaissance, par exemple. Dans le cas de citation, on sait que ce sont les villes qui citent, et le ministère classe dans le cas des citations. On voudrait également faire en sorte que les villes puissent citer l'intérieur de bâtiments. Les villes pour le moment peuvent le faire; pour l'extérieur et non pas pour l'intérieur. Donc, si une ville veut citer une petite église, l'intérieur, selon la loi actuelle, ne serait pas protégé. Selon le désir de la ville, il faudrait passer un classement. Alors, il y a des choses qu'il faut assouplir. Autre exemple, lorsque quelqu'un qui est propriétaire d'un monument classé veut faire une restauration, c'est très, très lourd comme procédure, et il faut demander à chaque fois des autorisations, des permis pour changer, par exemple, une poignée de porte. Alors, il y a des choses aussi qu'on veut assouplir de ce côté-là. Je pense que ça, c'est très important de le faire.

On veut également parler de patrimoine immatériel. Nous savons que, du côté de l'UNESCO, la notion du patrimoine immatériel est une notion qui fait vraiment son bonhomme de chemin. Et nous 
voulons aussi, nous, être capables de saisir l'occasion pour inclure, dans ce projet de loi, la question du patrimoine immatériel. C'est une partie importante de la culture traditionnelle quebécoise qui est chantée, contée, dansée ou interprétée en public, lors d'événements et de festivals annuels quilui sont consacrés. C'est le cas aussi des cultures autochtones qui reposent, pour l'essentiel, sur la transmission orale et les activités traditionnelles.

Également, nous voulons parler des paysages. C'est un point qui sera très important dans le projet de loi que nous préparons. La prochaine législation doit permettre de tenir compte de cette dimension afin que la gestion des arrondissements historiques et des sites de patrimoine intègrel'ensemble des composantes qui contribuent ou influencent la qualité patrimoniale de ces territoires. En effet, l'expérience acquise depuis trente ans démontre que la valeur patrimoniale d'un arrondissement historique n'est pas réductibleà la somme des seules valeurs architecturales et historiques des monuments qu'il contient.

Nous souhaitons de plus, avec ce projet de loi, faire en sorte que le Fonds du patrimoine culturel qui doit se terminer en 2011 devienne un programme permanent.

Dans un tout autre domaine, je souhaite accrôेtre le rayonnement de nos institutions et de nos artistes àl'étranger. Le marché québécois est de petite taille et nous devons aller à l'extérieur pour atteindre des masses critiques de clientèle. Or, la réputation de nos artistes et de nos institutions quebécoises est excellente. Étant donné que nous devons sans cesse nous battre pour conserver notre spécificité au sein du marché nord-américain, nous sommes sans cesse conviés à l'excellence et à l'innovation. Cen'est par hasard que nous étions à l'honneur cette année dans trois des plus importants festivals internationaux soit celui d'Avignon, pour le théatre, de Cervantino pour les arts de la scène et de Glasgow pour la musique traditionnelle.

Nous devons appuyer le talent québécois dans ses efforts de pénétration de nouveaux marchés et découvrir les artistes émergents. À cet égard, je saisis toutes les occasions qui me sont données pour découvrir les nouvelles formes d'art à titre de ministre, mais également et surtout à titre de passionnée des arts et de la culture.

Bref, je souhaite rassembler le plus grand nombre de Québécois à poser un regard neuf sur l'héritage que le temps nous a légué. Le patrimoine culturel du Québec est un précieux présent du passé dont nous avons la garde. Si, comme collectivité, nous n'en assurons pas la sauvegarde, qui doncle fera? 